Pathophysiology of Haemostasis and Thrombosis
Pathophysiol Haemost Thromb 2007-08;36:251-258

DOI: $\underline{10.1159 / 000252821}$
Received: April 28, 2009

Accepted after revision: September 17, 2009

\title{
The Role of Platelet and Fibrin Ultrastructure in Identifying Disease Patterns
}

\author{
E. Pretorius \\ Department of Anatomy, School of Medicine, Faculty of Health Sciences, University of Pretoria, Pretoria, South Africa
}

\author{
Key Words \\ Coagulation $\cdot$ Fibrin networks $\cdot$ Platelets $\cdot$ Scanning \\ electron microscopy $\cdot$ Ultrastructure
}

\begin{abstract}
Platelets and fibrin play an important role in the coagulation process where they are involved in the maintenance of haemostasis. Many diseases like cancer, thrombotic disease, bleeding disorders, asthma and even conditions like HIV/ AIDS are associated with ultrastructural changes in platelets and fibrin, and because of this altered morphology in many diseases, the question now arises whether ultrastructural and morphological analyses of platelets and fibrin networks have a place in contemporary medical research. The present work aims to demonstrate the usefulness of ultrastructural analyses in the broadening of knowledge of disease patterns and suggests that information gained by studying ultrastructure may enhance treatment regimes. We propose an altered haemostasis with changed coagulation factors resulting in a thrombotic event is present in the human body long before the actual event. Thus, by studying the coagulum and platelet profile, preventative actions can be taken. It is therefore concluded that morphology and ultrastructure do indeed have a place in medical research based on the fact that the knowledge obtained through these studies helps in the broadening of knowledge of disease patterns.
\end{abstract}

Copyright $\odot 2009$ S. Karger AG, Basel

\section{Introduction}

Platelets and fibrin play an important role in the coagulation process where they are involved in the maintenance of haemostasis [1]. They are anucleate and have a discoid shape in their resting state, travel as single particles and are activated by a number of stimuli resulting in the expression and/or activation of surface receptors, secretion of vasoactive substances, adhesion, aggregation and finally thrombus formation. The activation may be due to damage of the vessel wall or activation of the endothelium by chemicals, cytokines and also inflammatory processes $[2,3]$. Platelets are essential in the initial stages of thrombus formation, because they adhere and aggregate at sites of blood vessel wall injury and then serve as a surface for coagulation reactions, the overall rate of which determines the final structure of fibrin [4].

During thrombus formation, due to different stimuli (including damage to blood vessels), circulating platelets aggregate to form a large platelet clump or aggregate, change shape and form pseudopodia. Adhesion and activation are regulated by specific proteins on the platelet surface. Fibrinogen, the major plasma protein coagulation factor [5], plays a fundamental role in the coagulation process. Fibrin assembly (through the coagulation pathway and involvement of the platelets) from fibrinogen proceeds in a highly ordered fashion. Fibrin forms a

\section{KARGER \\ Fax +41613061234 \\ E-Mail karger@karger.ch}

www.karger.com
(C) 2009 S. Karger AG, Basel

$1424-8832 / 08 / 0365-0251 \$ 24.50 / 0$

Accessible online at:

www.karger.com/pht
E. Pretorius

BMW Building, Faculty of Health Sciences, University of Pretoria

PO Box 2034

0001 Pretoria (South Africa)

Tel. +27 12319 2533, Fax +27 12319 2240, E-Mail resia.pretorius@up.ac.za 
network which functions to stabilise the primary platelet plug. Although fibrin forms the core matrix of a thrombus, its structure depends also on the cellular elements embedded in its meshwork [4]. Morphological changes of fibrin networks may therefore occur due to several kinetic and modulating factors present in plasma. Also, fibrinolysis plays an important role in haemostasis. Leucocyte-derived enzymes, e.g. elastase, affect fibrinolysis by direct digestion of fibrin or indirectly modulate it by partial degradation of zymogens and inhibitors of coagulation and fibrinolytic proteases [4]. Many diseases like cancer, thrombotic disease, bleeding disorders, asthma and even conditions like HIV/AIDS are associated with changes in platelet and fibrin structure. Fibrin structure itself has been shown to play a role in the development of vascular complications. Proneness to the formation of tight and rigid fibrin networks, with abnormal architecture, has been shown to be independently associated with coronary heart disease [6]. Furthermore, abnormal gel structure, resulting in lower permeability of the network, has been observed in type I diabetic patients [7].

Because platelet and fibrin morphology is changed in certain diseases, the question now arises whether ultrastructural and morphological analyses of platelets and fibrin networks may have a place in contemporary medical research. The current work therefore aims to demonstrate the usefulness of ultrastructural analyses in the broadening of knowledge of disease patterns and suggests that information gained by studying ultrastructure may enhance treatment regimes.

\section{Methodologies Used to Study Platelet and Fibrin Ultrastructure}

Scanning electron microscopy (SEM) is a technique whereby the outer morphology of cells and structures can be studied. When studying platelets and fibrin structure, it is necessary to make a clot and to remove all reacted coagulation proteins so that the researcher is left with a fibrin network and, entrapped between the fibres, platelets. Fibrin networks can be created by adding human thrombin [8]. This human thrombin mixture is typically prepared from a single regular donor by calcium chloride activation of a euglobulin fraction of plasma obtained by aphaeresis. Each individual unit is tested and has to be nonreactive for hepatitis B surface antigen, HIV-1 antibody, HIV-2 antibody and HIV p-24 antigen, hepatitis C virus antibody and antibodies to Treponema pallidum.
These tests are performed by licensed assay methods. This thrombin is $20 \mathrm{U} / \mathrm{ml}$ and is made up in biological buffer (PBS) containing $0.2 \%$ human serum albumin. When thrombin is added to platelet-rich plasma, fibrinogen is converted to fibrin and intracellular platelet components, e.g. transforming growth factor, platelet-derived growth factor and fibroblast growth factor, are released into the coagulum.

Fresh platelet-rich plasma is prepared by drawing 40 $\mathrm{ml}$ of blood followed by centrifugation at $1,000 \mathrm{rpm}$ (maximum $\mathrm{RCF}=17.523 \mathrm{~g} ; 1,250 \mathrm{~g}$ ) for $2 \mathrm{~min}$. Equal volumes of platelet-rich plasma and human thrombin are mixed on a $0.2-\mu \mathrm{m}$ Millipore membrane to form the coagulum (fibrin clot). This Millipore membrane is then placed in a Petri dish on filter paper dampened with PBS to create a humid environment and placed at $37^{\circ} \mathrm{C}$ for 10 $\mathrm{min}$. This is followed by a washing process (to remove any proteins trapped within the fibrin network) where the Millipore membranes with the coagula are placed in PBS and magnetically stirred for varying times $(45,90$ and $120 \mathrm{~min}$ ) [8].

\section{Preparation of Washed Fibrin Clots for Scanning Electron Microscopy}

Washed fibrin clots are fixed in 2.5\% glutaraldehyde in Dulbecco's phosphate-buffered saline ( $\mathrm{pH}$ 7.4) for $1 \mathrm{~h}$. Each fibrin clot is rinsed thrice in phosphate buffer for $5 \mathrm{~min}$ before being fixed for $1 \mathrm{~h}$ with $1 \% \mathrm{OsO}_{4}$. The samples are rinsed thrice with distilled water for $5 \mathrm{~min}$ and are dehydrated serially in 30,50, 70 and $90 \%$ and three times in $100 \%$ ethanol. The SEM procedures are completed by critical point drying of the material, mounting and examining the tissue with SEM.

Figure 1 shows a typical platelet aggregate and fibrin network of a human control subject. Typical control platelet aggregates (fig. la) possess smooth membranes (label A) with pseudopodia (label B) protruding from the body of the aggregate. Figure $1 \mathrm{~b}$ depicts fibrin networks from the control human subject. Fibrin fibres can be morphologically divided into major, thick fibres (label C) and minor, thin fibres (label D). The major, thick fibres branch off from each other and they are typically seen as single fibres forming relative straight lines. Thin, minor fibres are much thinner than the major, thick fibres and are found sparsely distributed among the major fibres.

When studying ultrastructural disease patterns, platelet and fibrin from different diseases will typically react differently to that of the control platelets and fibrin net- 


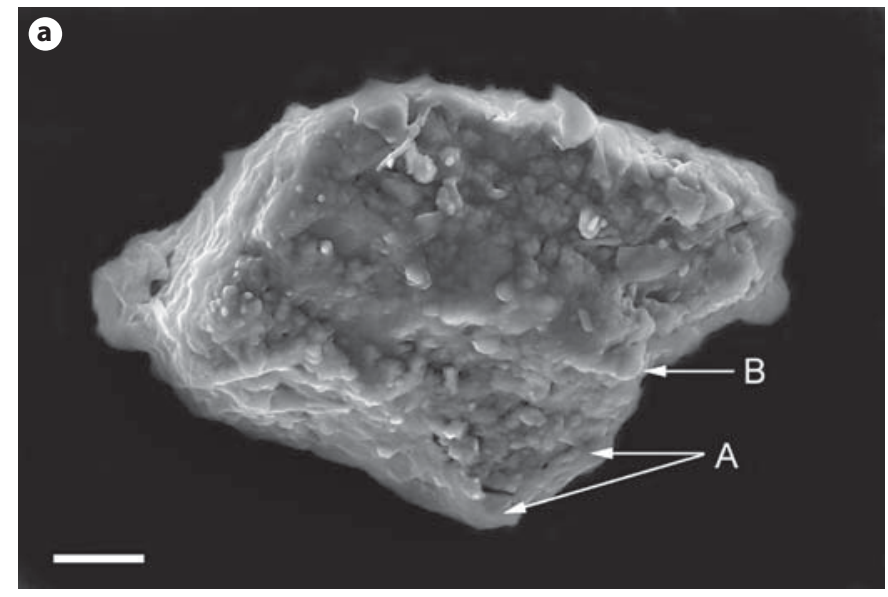

Fig. 1. SEM of a platelet aggregate (a) [25] and a control fibrin network (b) from a human control. A = Platelet aggregate with smooth membrane areas; $\mathrm{B}=$ pseudopodia formation; $\mathrm{C}=$ thick, major fibres; $\mathrm{D}=$ thin, minor fibrin fibres. Scale bars $=1 \mu \mathrm{m}$.

works, due to physiological differences in protein structure, absence or increases of certain coagulation proteins or presence of apoptotic or necrotic molecules in the coagulate. Although SEM analyses are not able to determine the type of molecule present/absent or overexpressed, it can give us an idea of the resultant structural changes in the body.

\section{Examples of How Morphology of Platelets and Fibrin Demonstrates Disease}

\section{Dysfibrinogenaemia}

During the haemostatic response, the formation of a primary platelet plug limits bleeding and provides a surface for clotting factors to assemble and become activated [9]. The initial platelet plug is stabilized by fibrin monomers, covalently cross-linked by factor (F) XIII, forming a platelet-fibrin thrombus. Defects in platelets as well as inherited deficiencies in coagulation factors, including fibrinogen, FII, FV, FV + FVIII, FVII, FX, FXI and FXIII deficiencies, generally lead to lifelong bleeding disorders, whose severity of bleeding symptoms is heterogeneous in platelet abnormalities but generally inversely proportional to the degree of the factor deficiency in rare bleeding disorders [9].

Genetic errors in the fibrinogen structure (congenital dysfibrinogenaemias) may occur when an abnormal fibrinogen molecule is present in the plasma, platelets or

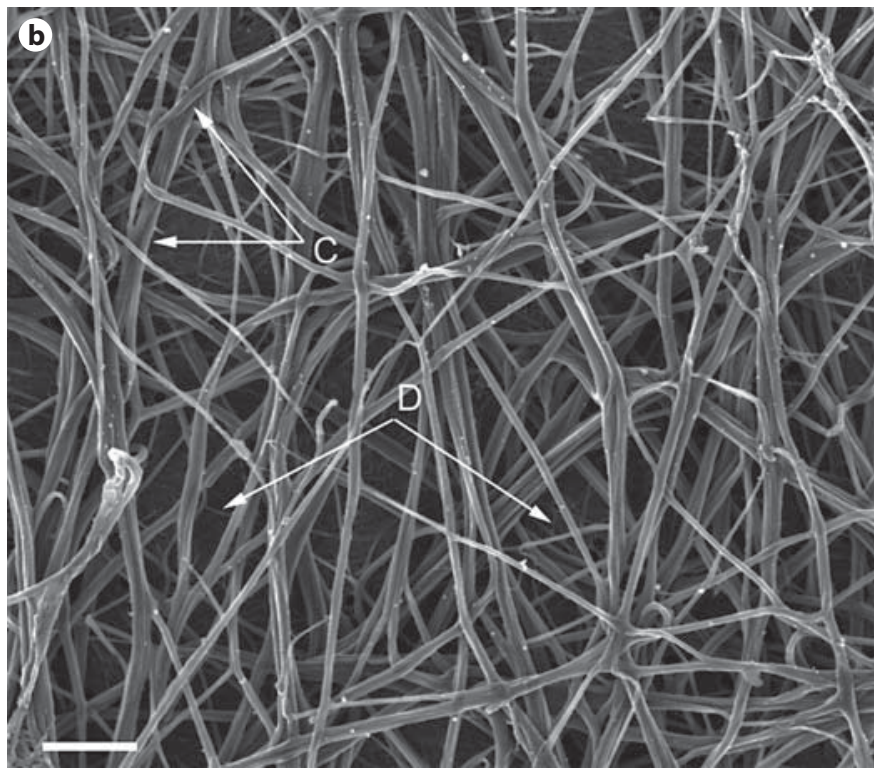

macrophages [10]. Dysfibrinogenaemias are not dependent on the concentration of fibrinogen making up the homodimer, but rather a genetic defect affecting one or more of the chains [11]. Genetic defects are usually caused by a single base mutation that results in the substitution of a single amino acid or are the result of stop codons (resulting in a truncated molecule) or small base deletions or additions that alter normal fibrinogen structure [12]. Typically, these structural modifications induce alterations in fibrinopeptide release, fibrin polymerization, fibrin cross-linking or fibrinolysis of the fibrin gel.

Clinically, patients with inherited dysfibrinogenaemia are frequently asymptomatic; however, some patients will exhibit bleeding, thromboembolic phenomena or both [12]. Most asymptomatic patients are heterozygous so that $50 \%$ of the fibrinogen molecules are normal, which is sufficient to maintain normal blood coagulation. Sometimes, however, heterozygotes will be symptomatic because the dysfibrinogen will interfere with one or more functional components of the normal fibrinogen molecule.

In 2006, Pretorius et al. [13] reported the characteristics of the fibrin network morphology in a Pretoria family with an amino acid substitution defect at position 139 on the chain where the cystein residue is replaced by tyrosine. This anomaly results in a disturbance of the interchain disulphide bond, an ultrastructural defect which interferes with fibrin polymerization. Clinical manifestations showed that some of the family members present- 


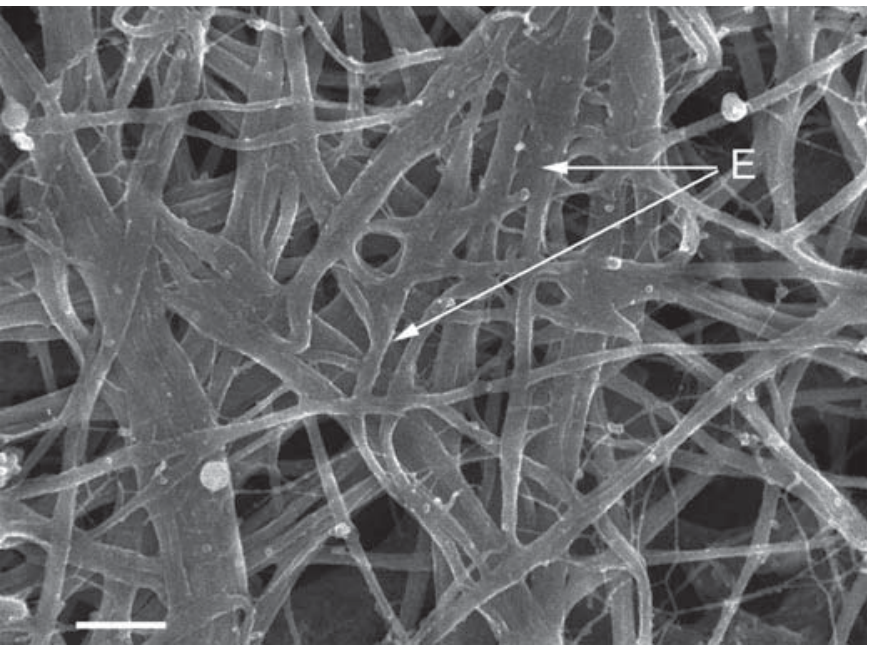

Fig. 2. SEM of fibrin fibres from a patient with dysfibrinogenaemia. $\mathrm{E}=$ Fibres fused in the longitudinal axis to form thicker bands and even sheets of matted fibrin. Scale bar $=0.5 \mu \mathrm{m}$.

ed with thrombosis as well as a bleeding tendency, while others were asymptomatic. Fibrin clot analysis revealed that in all family members a tighter fibrin network, with increased fibrin density and reduced pore size, were present. The fibres had a 'stellate' appearance where they converged. Also, some were fused longitudinally to form sheets of 'matted' fibrin [13]. Furthermore, there was a conspicuous absence of platelets. Fibrin dysfunction is associated with the development of vascular complications, while proneness to the formation of tight and rigid fibrin networks is independently associated with thrombotic disease. Figure 2 depicts tight fibrin networks where thick, major fibrin is longitudinally connected, forming tighter clot morphology than in figure $1 \mathrm{~b}$ (controls). Label $\mathrm{E}$ indicates fibres fused in the longitudinal axis to form thicker bands and even sheets of matted fibrin. This denser fibrin morphology suggests that during fibrinolysis the clot will be disassembled with more difficulty. This dense clot and possibly prolonged fibrin life may be the reason for thrombotic disease in this particular condition.

\section{Cancer}

Blood coagulation plays an important role in the occurrence of cancer. In patients with cancer, blood coagulation is activated to a prothrombotic state and a procoagulant environment may also promote cancer in different ways [14]. A prothrombotic state may include increased platelet activation, decreased fibrinolysis and decreased anticoagulants. It is known that blood coagulation proteins interact with cells in the vasculature to maintain haemostasis. However, many proteins that are involved in coagulation and anticoagulation, as well as fibrinolysis, are also found in extravascular tissues. In different organs, these proteins may be involved in cell signalling mechanisms, through interaction with cell receptors like protease-activated receptors [14]. Such interactions may drive inflammation, angiogenesis and cell proliferation.

It is also known that tumour cells require platelets for the development of metastases [15]. Research has furthermore suggested an unfavourable impact of thrombocytosis on prognosis, and thrombocytosis was associated with tumour aggressiveness $[16,17]$. Neoplastic cells in general seem to have a stimulatory effect on blood platelets.

In 2008, ten Cate and Falanga [14] mentioned that the potential procarcinogenic actions of proteases like thrombin may be counteracted by the anticoagulant and antiinflammatory actions of the protein C-thrombomodulin mechanism, and that in the blood of cancer patients, the balance is usually shifted towards a procoagulant direction [14]. There is therefore an excess of thrombin- and fibrin-forming activity which promotes venous thrombosis and may in the extravascular compartment stimulate cancer progression. Furthermore, ten Cate and Falanga [14] suggest that the activation of platelets and their interaction with leucocytes may propagate this process. The induction of specific anticoagulant proteins including thrombomodulin may therefore have effects on tumour growth or dissemination.

Interesting to note is that approximately $35 \%$ of patients with thrombocytosis have an underlying diagnosis of cancer, and increased levels of the cytokine IL- 6 have been reported in patients with reactive thrombocytosis $[18,19]$. Previously, it has also been demonstrated that serum IL-6 is elevated in a subgroup of patients with metastatic renal cell carcinoma and that administration of anti-IL-6 can normalize thrombocytosis [20]. Therefore, the overproduction of IL- 6 may at least in part be responsible for the paraneoplastic thrombocytosis associated with renal cell carcinoma. Thrombopoietin may also play a role in cancer. It is a peptide hormone that not only stimulates megakaryocyte proliferation and platelet production, but is also associated with cytoskeletal damage and apoptosis [21, 22].

In 2009, Pretorius et al. [23] demonstrated how platelet and fibrin morphology differ from controls in a patient with clear cell renal carcinoma with multiple liver, pulmonary and bone metastases. SEM analysis revealed an 


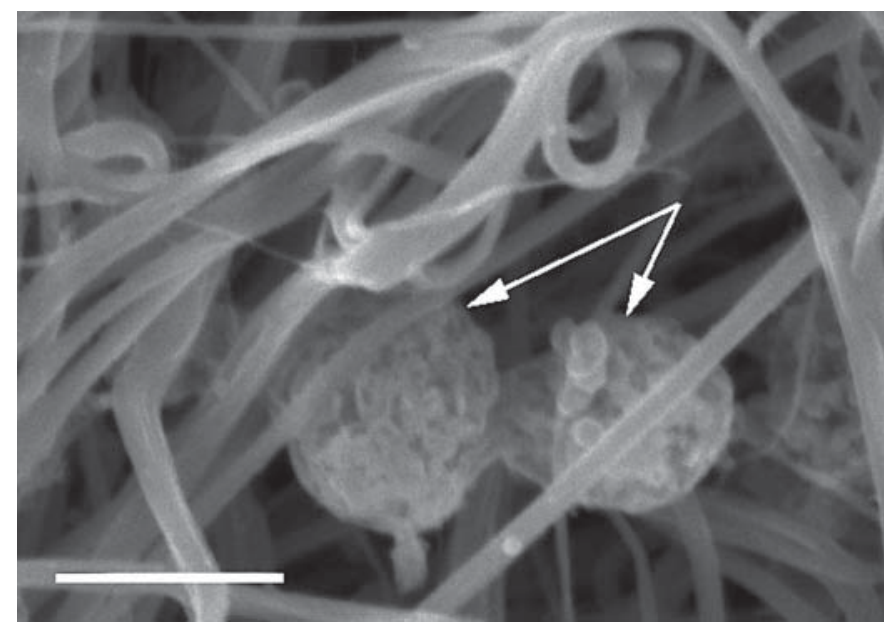

Fig. 3. Platelet aggregate from a patient with clear cell carcinoma. Arrows indicate swollen platelet aggregate with membrane breakages and no visible pseudopodia. Scale bar $=1 \mu \mathrm{m}$.

altered morphology of the platelet aggregates with multiple breakages in the platelet membrane, showing a pockmarked, crenated, prune-like appearance as opposed to the smooth, rounded globular membrane of the controls. Figure 3 depicts a platelet and fibrin network from clear cell renal carcinoma. The ultrastructural morphology of the fibrin-bound platelet aggregates in this patient with renal carcinoma therefore presented a disrupted cytoskeletal architecture (fig. 3) which appears to be similar to the apoptotic changes in programmed cell death as described by Bornman et al. [24] in 2007 and Pretorius et al. [25] in 2008. Arrows indicate swollen platelet aggregate with membrane breakages and no pseudopodia visible. The authors suggested that these features may well be a distinct ultrastructural haematological manifestation of a previously unidentified paraneoplastic syndrome [23].

\section{Asthma}

Platelets play an important role in inflammatory conditions like asthma and there is a vast amount of clinical data that reveal that platelet activation accompanies allergen-induced bronchoconstriction in humans $[26,27]$. In animal models of allergic asthma, the importance of platelets for acute bronchoconstriction, airway hyperresponsiveness and bronchial wall remodelling has been stressed [27, 28]. According to Pitchford [29] in 2007, the roles of platelets in asthma are distinct from their classically known actions performed during thrombosis and

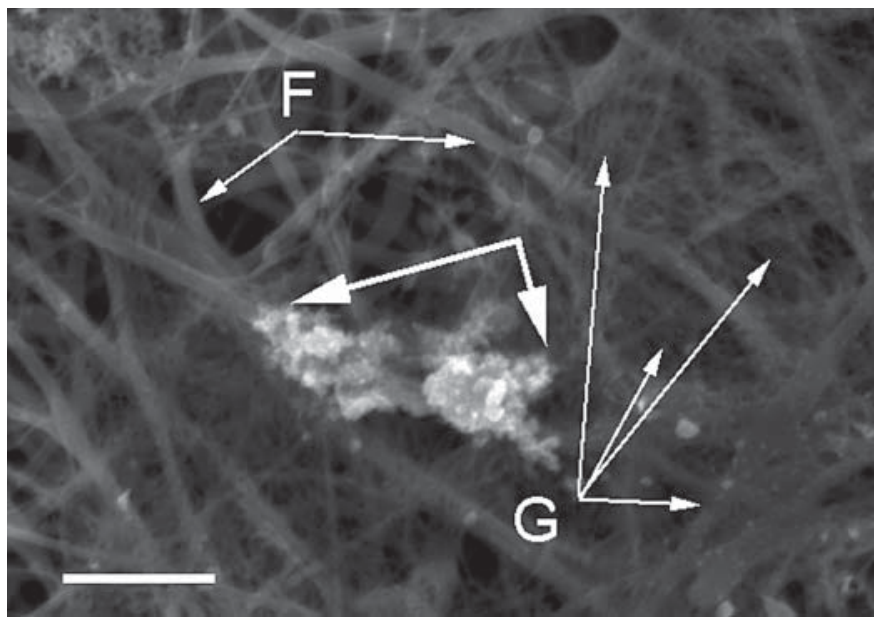

Fig. 4. Platelet aggregate and fibrin network from an uncontrolled asthmatic. Thick arrows show course, loosely arranged platelet aggregate. $\mathrm{F}=$ Major fibres; $\mathrm{G}=$ minor fibres forming a matted, net-like fibrin network. Scale bar $=1 \mu \mathrm{m}$.

haemostasis, and include the expression of adhesion molecules and contact-dependent activation of leucocytes, the release of a plethora of inflammatory mediators, activation in cells of the adaptive immune response and the ability to migrate and undergo chemotaxis. The author also mentions that clinical data from patients suffering from asthma, allergic rhinitis and allergic dermatitis reveal changes in platelet behaviour and function during or after allergen exposure. It is therefore useful to examine platelets and fibrin to study a disease such as asthma. Fibrinogen itself is also widely recognised as a marker for systemic inflammation as it is considered an acute phase protein. In 2004, Pitchford et al. [30] mentioned that there is evidence of platelet recruitment to the lungs of asthmatics after allergen exposure, suggesting that platelets participate in various aspects of asthma. Furthermore, it has also previously been suggested that platelet activation may contribute to airway remodelling in asthma [31].

Recently, Pretorius and Oberholzer [32] have investigated the ultrastructure of platelets and fibrin networks using the asthmatic BALB/c mouse model. They showed that in human asthma and in an animal model of asthma, morphology of fibrin and platelets is very similar. Figure 4 shows a platelet and fibrin network of uncontrolled human asthma. In human asthma, minor fibres have a net-like appearance (label G) covering the major fibres (label F), while the platelets seem to form loosely connected, granular aggregates (thick arrows). 


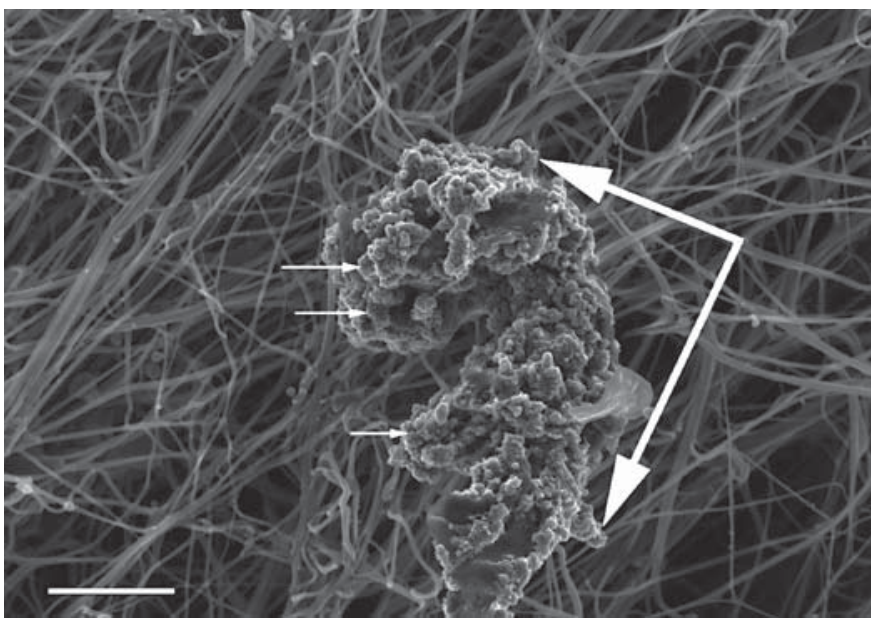

Fig. 5. Platelet aggregate from a patient with HIV. Thick arrows show platelet aggregate; thin arrows show membrane with bleblike extensions on the surface. Scale bar $=1 \mu \mathrm{m}$.

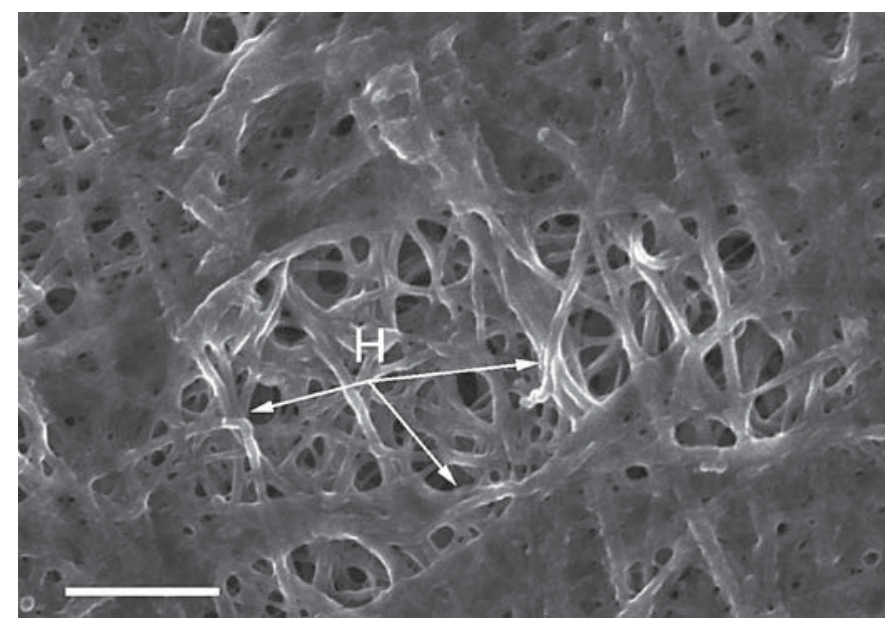

Fig. 7. Fibrin network from a dog immediately after suffering an ischaemic stroke. $\mathrm{H}=$ Thick, mat-like fibrin. Scale bar $=1 \mu \mathrm{m}$.

\section{HIV/AIDS}

Several haematological abnormalities associated with HIV have been documented, however, the mechanisms responsible for cytopaenia in these patients are complex and not always completely understood. Thrombocytopaenia, which occurs in about $40 \%$ of patients with HIV infection, may be caused by increased peripheral platelet destruction, a defect in platelet production due to the impaired formation of platelets by HIV-infected megakaryocytes, or a combination of these. In 2008 and 2009,

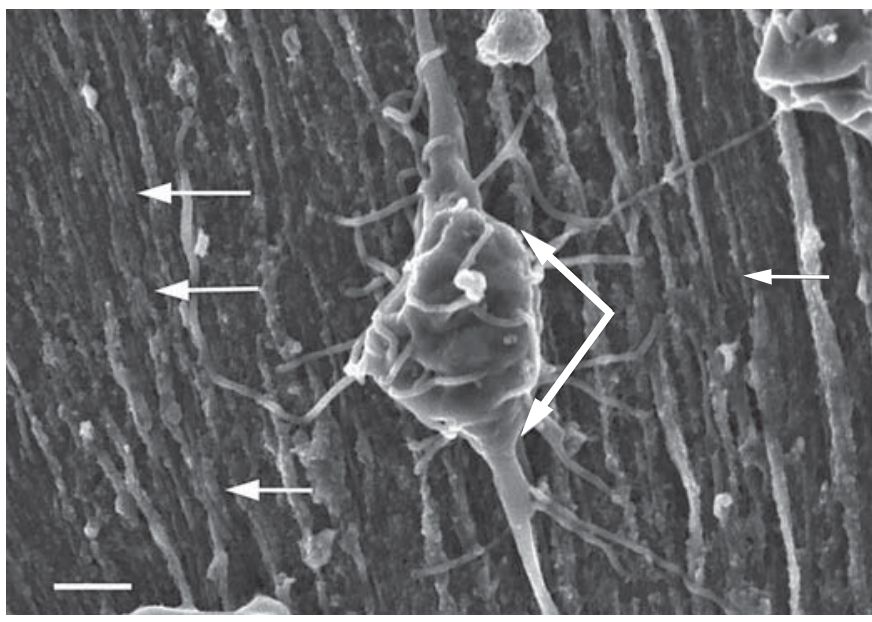

Fig. 6. Fibrin network from a rat 3 days after burn wound. Thin arrows show fibrin areas; thick arrows show platelet aggregate. Scale bar $=1 \mu \mathrm{m}$.

Pretorius et al. [25, 33] studied the morphology of platelets and fibrin networks in HIV/AIDS patients. The results indicated that although the platelets do aggregate, the morphology was changed with membrane blebbing (small areas on the membrane that bulge outwards), as well as torn cellular membranes. From the literature it is known that membrane blebbing is typically associated with apoptosis. They concluded that the altered morphology of platelet aggregates in HIV patients may be related to thrombocytopaenia as a result of peripheral platelet destruction [25]. Figure 5 demonstrates fibrin networks and platelet aggregate (thick arrows) of a HIV patient (thin arrows show membrane with bleb-like extensions on the surface).

\section{Burn Wounds}

The traditional approach to haemostatic disorders in the injured burn wound patient has focused on bleeding rather than a hypercoagulable state [34] and that coagulation abnormalities exist in patients with severe infection. Haemorrhage may be successfully treated in patients following trauma, however, thrombosis in the microcirculation often contributes to end-organ damage with irreversible ischaemic changes that may lead to death [34]. Particularly burn patients are at high risk of developing thromboembolic complications and also have significantly altered hypercoagulability; vascular integrity is also changed by burn injury [35]. Hypercoagulability of lymph and plasma presents in thermally damaged tissue 2-3 h following scalding [36]. These findings correlate 
well with the increase of kinins in the lymph, indicating that the Hageman factor may serve as a common activator of the kinin and the coagulation-fibrinolytic system. The clots that are formed initially have to be removed in the healing process. This is done by enzymatic digestion by the proteolytic enzyme plasmin, which exists in the plasma in its inactive form (plasminogen) [36]. It has, however, been known for 20 years that there exists an inhibition of fibrinolysis in thermal injury both in patients' plasma and in human burn blister fluid. A changed fibrin morphology was recently noted in a rat model of burn wound. Although platelet morphology did not change (fig. 6, thick arrows indicating platelet aggregate), fibrin networks were not typical of controls. Fibrin networks formed thickened, matted fibrin layers (thin arrows).

\section{Thrombosis}

Platelets play an important role in the development of thrombosis, atherosclerosis, hypertension, heart attack and stroke [37]. Thrombosis is a leading cause of death worldwide and complicates atherosclerotic disease, heart failure, cancer, surgery and pregnancy [38]. A recent animal study by Pretorius et al. deals with the ultrastructure of the fibrin networks of a dog that suffered ischaemic stroke. Fibrin networks and platelets were studied immediately after the stroke (fig. 7), and in this condition, the fibrin networks have a dense, mat-like appearance (label $\mathrm{H})$ without the typical distinguishable separate major and minor fibrin layers.

\section{Predictive Value of Platelet and Fibrin Morphology in Disease}

The previous paragraphs evidenced that disease involving platelets and fibrin networks can be visualized by studying ultrastructure. It is therefore suggested that in certain conditions like stroke the study of the ultrastructure of the coagulation system may have value as a predictive tool and may be used in the development of a screening tool. Such a screening procedure would not only be cheap, but could potentially warn patients of a possible thrombotic event, long before any symptoms are prevalent. Here it is therefore suggested that changes in haemostasis and coagulation factors that will result in a thrombotic event are present in the human body long before the actual event. By studying the coagulum and platelet profile preventative actions can be taken. Such a predictive test would involve only one tube of blood and a relatively low-range SEM. Such a screening tool can potentially save thousands of lives. It is therefore concluded that morphology and ultrastructure do indeed have a place in medical research based on the fact that the knowledge obtained through these types of studies helps in the broadening of knowledge of disease patterns, and it is suggested that information gained by studying ultrastructure may enhance treatment regimes.

\section{References}

1 Herd CM, Page CP: Pulmonary immune cells in health and disease: platelets. Eur Respir J 1994;7:1145-1160.

-2 Camera M, Giesen PL, Fallon J, Aufiero BM, Taubman M, Tremoli E, Nemerson Y: Cooperation between VEGF and TNF-alpha is necessary for exposure of active tissue factor on the surface of human endothelial cells. Arterioscler Thromb Vasc Biol 1999;19:531537.

3 Butenas S, Mann KG: Blood coagulation. Biochemistry 2002;67:3-12.

4 Wohner N: Role of cellular elements in thrombus formation and dissolution. Cardiovasc Hematol Agents Med Chem 2008;6: 224-228.

5 Lowe GD, Rumley A, Mackie IJ: Plasma fibrinogen. Ann Clin Biochem 2004;41:430440 .
6 Fatah K, Hamsten A, Blombäck B, Blombäck M: Fibrin gel network characteristics and coronary heart disease: relations to plasma fibrinogen concentration, acute phase protein, serum lipoproteins and coronary atherosclerosis. Thromb Haemost 1992;68:130135.

7 Jörneskog G, Fagrell B: Discrepancy in skin capillary circulation between fingers and toes in patients with type 1 diabetes. Int $\mathrm{J}$ Microcirc Clin Exp 1996;16:313-319.

8 Pretorius E, Briedenhann S, Marx J, Smit E, van der Merwe CF, Pieters M, Franz RC: Ultrastructural comparison of the morphology of three different platelet and fibrin fiber preparations. Anat Rec (Hoboken) 2007;290: 188-198.

-9 Peyvandi F, Cattaneo M, Inbal A, De Moerloose P, Spreafico M: Rare bleeding disorders. Haemophilia 2008; 14(suppl 3):202210.
10 McDonagh J, Carrel N, Lee MH: Dysfibrinogenemia and other disorders of fibrinogen structure and function; in Colman RW, Hirsh J, Marder V, et al (eds): Haemostasis and Thrombosis: Basic Principles and Clinical Practice, ed 3. Philadelphia, Lippincott, 1994.

11 Haverkate F, Samama M: Familial dysfibrinogenemia and thrombophilia. Report on a study of the SSC Subcommittee on Fibrinogen. Thromb Haemostat 1995;73:151-161.

12 Roberts HR, Stinchcombe TE, Gabriel DA: The dysfibrinogenaemias. $\mathrm{Br} \mathrm{J}$ Haematol 2001;114:249-257.

13 Pretorius E, Briedenhann S, Marx J, Franz RC: Structural changes in the fibrin network of a Pretoria family with dysfibrinogenemia: a scanning electron microscopical study. Ultrastruct Pathol 2006;303:167-176. 
14 ten Cate H, Falanga A: Overview of the postulated mechanisms linking cancer and thrombosis. Pathophysiol Haemost Thromb 2008;36:122-130.

15 Hilgard P: The role of blood platelets in experimental metastases. Br J Cancer 1973;28: 429-435.

16 Besalah K, Leray E, Fergelot P, RiouxLeclercq N, Tostain J, Guillé F, Patard JJ: Prognostic value of thrombocytosis in renal cell carcinoma. J Urol 2006;175:859-863.

-17 Matowicka-Karna J, Mantur M, Darewicz B, Kemona H: Morphological parameters of blood platelets before and after renal artery embolization in patients with renal cancer. Rocz Akad Med Bialymst 1999;44:55-63.

18 Schafer AI: Thrombocytosis. N Engl J Med 2004;350:1211-1219.

$\checkmark 19$ Hollen CW, Henthorn J, Koziol JA, Burstein SA: Elevated serum interleukin- 6 levels in patients with reactive thrombocytosis. $\mathrm{Br} J$ Haematol 1991;79:286-290.

20 Blay JY, Favrot M, Rossi JF, Wijdenes J: Role of interleukin- 6 in paraneoplastic thrombocytosis. Blood 1993;82:2261-2262.

21 Jameson JL, Johnson BE: Haematological paraneoplastic syndromes; in Kasper DL, Braunwald E, Fauci AS, Hauser SL, Longo DL, Jameson JL, Loscalzo J (eds): Harrison's Principles of Internal Medicine, ed 17. New York, McGraw Hill, 2008, p 622.

-22 Kalazhny Y, Ravid K: Role of apoptotic processes in platelet biogenesis. Acta Haematol 2004;111:67-77.
23 Pretorius E, Bornman MS, Reif S, Oberholzer HM, Franz RC: Ultrastructural changes of platelet aggregates and fibrin networks in a patient with renal clear cell adenocarcinoma: a scanning electron microscopy study. Microsc Res Tech 2009;72:679-683.

-24 Bornman MS, Pretorius E, Marx J, Smit E, van der Merwe CF: Ultrastructural effects of DDT, DDD and DDE on neural cells of the chicken embryo model. Environ Toxicol 2007;22:328-336.

25 Pretorius E, Oberholzer HM, Smit E, Steyn E, Briedenhann S, Franz CR: Ultrastructural changes in platelet aggregates of HIV patients: a scanning electron microscopic study. Ultrastruct Pathol 2008;32:75-79.

26 Pitchford SC, Yano H, Lever R, Riffo-Vasquez Y, Ciferri S, Giannini S, Momi S, Spina D, O'Connor B, Gresele P, Page CP: Platelets are essential for leukocyte recruitment in allergic inflammation. J Allergy Clin Immunol 2003;112:109-118.

27 Pitchford SC, Momi S, Baglioni S, Casali L, Giannini S, Rossi R, Page CP, Gresele P: Allergen induces the migration of platelets to lung tissue in allergic asthma. Am J Respir Crit Care Med 2008;177:604-612.

28 Pretorius E, Ekpo OE, Smit E: Comparative ultrastructural analyses of platelets and fibrin networks using the murine model of asthma. Exp Toxicol Pathol 2007;59:105114.

29 Pitchford SC: Defining a role for platelets in allergic inflammation. Biochem Soc Trans 2007;35:1104-1108.
30 Pitchford SC, Riffo-Vasquez Y, Sousa A, Momi S, Gresele P, Spina D, Page CP: Platelets are necessary for airway wall remodeling in a murine model of chronic allergic inflammation. Blood 2004;103:639-647.

31 Morley J, Sanjar S, Page CP: The platelet in asthma. Lancet 1984;i:1142-1144.

32 Pretorius E, Oberholzer HM: Ultrastructural changes of platelets and fibrin networks in human asthma: a qualitative case study. Blood Coagul Fibrinolysis 2009;20:146-149.

-33 Pretorius E, Oberholzer HM, Smit E, Steyn E, Briedenhann S, Franz RC: Investigating the ultrastructure of platelets of HIV patients treated with the immuno-regulator, Canova: a qualitative scanning electron microscopy study. Histol Histopathol 2009;24: 399-405.

34 Dries DJ: Activation of the clotting system and complement after trauma. New Horiz 1996;4:276-288.

-35 Faucher LD, Conlon KM: Practice guidelines for deep venous thrombosis prophylaxis in burns. J Burn Care Res 2007;28:661663.

36 Arturson MG: The pathophysiology of severe thermal injury. J Burn Care Rehabil 1985;6:129-146.

37 Duhamel TA, Xu YJ, Arneja AS, Dhalla NS: Targeting platelets for prevention and treatment of cardiovascular disease. Expert Opin Ther Targets 2007;11:1523-1533.

-38 Bailey AL, Scantlebury DC, Smyth SS: Thrombosis and antithrombotic therapy in women. Arterioscler Thromb Vasc Biol 2009;29:284-288. 